\title{
Exploration of Library Outreach to Nontraditional Students
}

\section{Andria L. Tieman and Megan E. Black}

Andria L.Tieman (atieman@ providence.edu) is Commons Librarian for Digital Research and Education and Megan E.Black(megblack615@ gmail.com) is Commons Librarian for Research and Education, Providence College, Providence, Rhode Island.
Reference \& User Services Quarterly, vol. 56, no. 3, pp. 198-205

(c) 2017 American Library Association. All rights reserved.

Permission granted to reproduce for nonprofit, educational use.
In 1976, Malcolm Knowles, known for his research on adult education and learning, predicted that the library would become, "the most rapidly expanding educational institution of all in [the United States]," regarding working with nontraditional students. His prediction has not come to fruition. In fact, there was little published regarding librarians supporting adult students from the mid-1980s until 2000, when librarian Dorothy S. Ingram published "The Andragogical Librarian," and 2010, with the publication of researcher Nicole Cooke's article, "Becoming an Andragogical Librarian: Using Library Instruction to Combat Library Anxiety and Empower Adult Learners," published in 2010. The literature consulted includes research focused on adult education in academia, library anxiety, and library literacy for nontraditional students, spanning from the mid-1970s through the present day. Nontraditional students at Providence College range in age from their twenties through eighties; therefore we did not include research that exclusively looks at library instruction for students who are age fifty-five and older returning to higher education. Providence College's School for Continuing Education works with students who meet in a traditional classroom or blended online and classroom settings, and the library currently works exclusively with face-to-face classes, so research that focuses on online students or distance students was not included in the literature scan. We also excluded research that focuses on outreach to graduate students as they have different needs and experiences than students seeking bachelor's degrees.

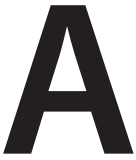
dult education researcher, Gordon Darkenwald defines nontraditional students by sociocultural responsibilities instead of age. In Darkenwald's definition, a nontraditional college student is an individual returning to formal education after a break in education to take on roles typical of an adult in society. ${ }^{2}$ These responsibilities include, but are not limited to, full-time employment, parenthood, and other financial responsibilities. Often times these responsibilities take priority over academics. $^{3}$ Due to the break from formal education and added responsibilities not characteristic of traditional college students, the research focusing on library instruction and outreach for the traditional student is not relevant. Rather, the focus for instructors and librarians needs to be on research regarding how to most effectively reach nontraditional students. Cooke points out that while the number of nontraditional students working to complete bachelor's degrees is increasing, most 
of the research focuses on traditional college students and, "the specific needs and characteristics of adult learners are often overlooked."14 Librarians are key in easing the anxiety often faced by this population.

\section{LITERATURE REVIEW}

\section{Literature on Andragogy}

Malcolm Knowles is credited for developing the theory of andragogy, the teaching style specific to adult students, although the theory first appeared in education literature in $1933 .^{5}$ The research surrounding how adult students learn finds that they prefer a more informal and collaborative approach to education, and "benefit from different institutional services and teaching styles than those offered to traditional students." Knowles created a andragogical model that outlines the specific learning styles and needs of the nontraditional student. This model is based on several principles that make it distinct from pedagogy, which include: the need to know, self-concept, prior experiences, readiness to learn, the orientation to learning, and motivation. ${ }^{7}$

- Need to know: Adult students need to know why they are learning something, and are much more likely to put forth considerable effort into the learning process once they see the benefits. Knowles argues that instructors first need to communicate the purpose for learning an objective before presenting it. The most effective way to do this is to facilitate a learning experience in which the adult students, "discover for themselves the gaps between where they are now and where they want to be."

- Self-Concept: The second principle focuses on selfconcept. Most adults have the self-concept that they are responsible for their own decisions, and this principle of self-concept focuses on teaching in a way that empowers this aspect of the student. Adult students struggle with learning activities that represent the teacher bestowing knowledge, or that mimic a model in which the student is completely dependent on the instructor. Knowles argues that this type of teaching-learning dynamic denies adult students of their self-concept and therefore prevents buy-in. Attempting to teach adult students as one would teach children creates internal conflict with the psychological need to be self-directing. Instructors who work with adults will find more success in facilitating a learning environment that helps adults to become selfdirecting learners.

- Prior Experiences: Most nontraditional classes have a wide age range, and therefore a wide range of life experiences. Adults tend to self-identify based on life experiences, whereas children identify based on external factors. Knowles argues that classrooms that ignore or devalue an adult student's life experience results in the student feeling ignored or devalued. The best educational techniques for adult students require that they bring their unique life experiences to the classroom and also challenge them to expand their preconceived ideas.

- Readiness to Learn: An adult student's readiness to learn centers around the ability to address real-life situations. Knowles recommends simulation or problem-based learning to engage students' readiness to learn something. He explains that this teaching style is effective because it bases learning on "developmental tasks associated with moving from one developmental stage to the next. The critical implication of this assumption is the importance of timing learning experiences to coincide with those developmental tasks."

- Orientation to Learning: Adult students tend to be problem-centered or life-centered in their orientation to learning, whereas children are subject-centered: "Adults are motivated to learn to the extent that they perceive that learning will help them perform tasks or deal with problems that they confront in their life."10 This orientation is why most adults return to the traditional classroom, and is what keeps them motivated through the process.

- Motivation: Most adults have a desire for personal growth and development, and respond to both external motivation, such as a better job or promotion, and internal motivation, such as self-esteem or job satisfaction. The primary block to this motivation is their own low self-esteem or negative self-concept as students.

\section{Literature on Library Anxiety}

The majority of the research on library anxiety focuses on undergraduate students, international students, or other specific demographics that do not include nontraditional students. The library anxiety research that addresses the nontraditional student population is primarily from librarian Constance A. Mellon's work in the 1980s. There are some scholarly articles regarding library anxiety published since her work, but they are predominantly literature reviews. The digital divide and the migration of library resources from the physical world to online creates another level of library anxiety. The research regarding the digital divide and libraries in the United States, however, focuses on public libraries.

Mellon's research resulted in the term, "library anxiety," which is characterized by, "feeling that one's library skills are inadequate compared to those of one's peers." ${ }^{\text {"11 }}$ Mellon was originally hired at the University of Tennessee at Chattanooga in 1981 to develop a library instruction program to reach all student levels. The gra duate nursing school students were the ones who tipped her off that something was getting missed in the library instruction. She explained at a Library Orientation Exchange (LOEX) conference that these students all had the same story: "I've been out of schools so long. ... I hate to bother the people at the reference desk with all these dumb questions, but I just don't know where to begin." 12 This sparked a two-year qualitative study of six thousand students on campus regarding their perceptions of 


\section{FEATURE}

the library and library research. Instructors had their students keep journals regarding their feelings in the research process, which were then reported back to Mellon. She found that the majority of all students felt that they were the only one who did not understand how to use the library." "I was scared to ask questions. I didn't want to bother anyone. I also didn't want to them to think I was stupid."'3 The library anxiety stemmed from four causes: "the size of the library; a lack of knowledge about where things were located; how to begin; and what to do." ${ }^{14}$ This anxiety interferes with students' ability to do research, and therefore their overall learning.

Mellon believes that because librarians are so familiar with the resources, they forget what it's like to be overwhelmed by them. She and her colleagues agreed that the typical fifty-minute library instruction sessions do not provide enough time to develop a real working grasp of using library resources, but the research suggested that these sessions made the librarians seem more approachable to students. This resulted in Mellon redesigning the library instruction session as a "warmth seminar" where librarians still teach library tools, ${ }^{15}$ but also include a component about library anxiety in an effort to help students feel more comfortable with the library and asking for help when they don't know how to do something.

Technostress, the fear and anxiety around using technology, is closely related to library anxiety, especially as library resources move to digital formats. Brian Quinn found that many nontraditional students have the added stress of learning how to use a computer in addition to the pressures of completing their assignments. Quinn points out that technostress is a subjective reaction to a social situation. Consequences of this anxiety regarding technology are real and may become a self-fulfilling prophecy. Nontraditional students who suffer from technostress often have difficulty mastering the online catalog and the databases. OPACs don't adjust or fix spelling errors, and many students use a search string of words instead of keywords. Both of these habits often result in few or no search results, which may reinforce feelings of technostress, anxiety, and inadequacy. ${ }^{16}$ These negative feelings and technostress can become cyclical and inhibit students' ability to learn.

Librarians who work with nontraditional students need to be able to identify symptoms of technostress. This is vital because a student will not succeed with just the information on how to conduct a proper research strategy. Also, librarian and researcher Charlotte Diana Moslander found that many adult students perceive their technostress and library anxiety as unique to them, and "will avoid asking for help ('being exposed') at all costs." ${ }^{17}$ This means the librarian must not only explain how to use the technology when teaching library instruction, but also avoid jargon and not show-off with the technology. ${ }^{18}$ Similar to Mellon's previously mentioned warming seminars, Quinn recommends that librarians focus on how they convey information to the students. "The overall tone and manner of the librarian, the physical and verbal cues that he or she uses, can play a vital role in reducing the stress level of the adult learner."19 Quinn recommends that the students perform various tasks during the instruction session so the librarian can gauge if students need additional support or not. The same task may need to be repeated several times by both the librarian and student to ensure the information is grasped.

\section{LITERATURE ON LIBRARY INSTRUCTION AND NONTRADITIONAL STUDENTS}

There is a gap in the research regarding librarians' work with nontraditional students after Knowles's support of librarianship and andragogy and Mellon's research on library anxiety. This was not discussed until the early 2000s, and was not given prominent focus until Cooke's 2010 article focusing on andragogy and librarianship. There is some research from the critical librarianship movement that touches on nontraditional aged students, but most of this research looks at populations such as adult students whose native language is not English or other underserved groups within nontraditional students. It is also important to note that the research on library instruction designed for nontraditional students focuses on in-classroom instruction. There are arguments that instruction is the gateway to curbing library anxiety and ultimately the tool to get nontraditional students into the library and to ask for help.

Library instruction ranges from tours to one-time instruction sessions to to formal, credit-bearing library instruction courses and research classes. This section of the literature review will only focus on formal instruction in the classroom as our current effort in reaching nontraditional students is based in formal instruction. Nicole Cooke explored thirty-five years of research in both adult education and library science in an effort to find ways to specifically reach nontraditional students with library instruction in her article "Becoming an Andragogical Librarian: Using Instruction as a Tool to Combat Library Anxiety and Empower Adult Learners." She points out that much of the adult education literature discusses the different campus resources available to students; it typically does not mention libraries as one of these resources. Much of the library literature that deals with adult learners focuses on the topic from the perspective of public libraries, which offer different services and serve different needs than academic libraries. Cooke argues that the majority of academic instruction librarians do not utilize andragogical methods when teaching, but, due to trends in librarianship, their role is shifting from information provider to learning facilitator, which aligns with the tenets of adult education.

Nontraditional students typically have competing priorities such as a full-time job, family, and school; therefore, they do not have the free time to experiment and explore resources available to them as more traditional students do. Cooke says, "Instruction librarians should strive to make the learning meaningful, immediate and relevant to their needs 
and should strive to address broader information needs,"20 when working with nontraditional students. While relevancy is important when teaching all students, it is particularly important to nontraditional students due to their competing demands. To address this, Cooke argues that the elements of successful library instruction include, "praxis, immediacy, and engagement," so that students actively participate and practice working with library tools, and see the immediate and long-term with the idea of creating relevant content and strive to have the learners interact with and utilize that content effectively and repeatedly."21 Praxis is crucial because "adult learners tend to perform praxis in their daily lives by engaging in an actions [sic] and looking at the implications and consequences of those actions." 22 Content that promotes student engagement helps to create enthusiasm and shows the immediacy and importance of the content taught. The combination of enthusiasm and relevancy in the content makes it easier for students to interact with the information, and integrates the research process or tool into their knowledge base.

Nontraditional students typically have less technology knowledge, which puts them at a disadvantage as library resources increasingly move to digital formats. The lack of technology knowledge causes anxiety, often called technostress, which creates an additional level of stress for nontraditional students attempting to access library resources. Due to time constraints nontraditional students typically access library resources remotely, creating additional barriers to information beyond library anxiety. Cooke suggests that interactive library instruction is a way to quell library anxiety and technostress: "As adult learners actively participate and learn, they will gain confidence and independence with navigating the library and technology tools." ${ }^{23}$ Cooke cites the Middle States Commission on Higher Education to suggest that, ultimately, successful library instruction is "more than technological competence or on-line research. It encourages critical thinking and reflection in the context of the increasingly extensive amounts of information now available through a wide range of technologies."24

Librarians at McGill University Library created a pilot program with their Centre for Continuing Education (CCE), based on Cooke's call for case studies in her 2010 article. Students in the CCE can be undergraduate, graduate, or non-degree seeking depending on their program, but primarily fall within the description of nontraditional students described in this literature review. Canadians ages twenty-five to sixty-four enrolled in higher education are an increasing population on Canadian college campuses. The growth rate was about 3.8 percent per year from 1998 to 2008 , which is comparable to similar age demographics in the United States. ${ }^{25}$ McGill librarians found that while enrollment at the CCE was increasing, library outreach to the students and faculty was limited, as was knowledge about the library and its resources within the CCE. The librarians, program coordinators, and faculty worked together to identify needs and opportunities for partnerships. The pilot program included embedded library instruction using andragogical teaching techniques, increased marketing of services, and targeted collection development. Tailored library instruction utilized the core principle of andragogy as outlined by Cooke and Knowles. The librarians collected feedback, both with formal surveys and anecdotal conversations. The collaboration helped librarians better understand the unique needs and challenges of CCE students and faculty with the dedicated liaison program. All instructors reported that students' research improved after tailored library instruction. Students and instructors informally reported a better understanding of the library and its resources available. The authors plan to conduct more formal assessment of their continued efforts now that relationships with the CCE have been made.

Andragogy provides a foundation from which lesson plans can be created for nontraditional students. Problembased learning, where students practice the content as part of the lesson, empowers students to be more self-directed in the classroom, which fulfills one of the core principles of andragogy. Giving students a research scenario to solve is one way to encourage them to explore and become familiar with the library's resources, according to information literacy librarian, Lauren Hays. She recommends requesting that students reflect on their process to further empower them to be self-directed in their learning process. Showing students the whole picture and then breaking down the information to demonstrate the individual steps helps nontraditional students understand how this information is relevant. This fulfills the need to know as discussed by Knowles. Hays recommends showing an entire annotated bibliography before explaining how to achieve the different parts to create one. Student reflection is also important when teaching this way because it helps them "better understand how what they are learning is affected by what they already know and how what they already know might need to change with the new information they are learning." ${ }^{26}$ This type of learning is called double-loop learning, and thoroughly encompasses the core principles of andragogy. Overall, librarians that act as a facilitators or consultants when working with nontraditional students, by providing relevant content, recognizing the prior experience students bring to the classroom, and creating an open feedback loop, will provide the most effective instruction.

\section{PROVIDENCE COLLEGE'S SCHOOL FOR CONTINUING EDUCATION}

\section{Perspectives in Western Civilization Overview}

Perspectives in Western Civilization is a three-credit course that serves as Providence College's (PC) School of Continuing Education (SCE) complement to the Development of Western Civilizations (DWC) course that regular undergraduates (referred to by the college and for the rest of this article as Day Students) take over the course of their first two 


\section{FEATURE}

years at PC. DWC is a rigorous curriculum that consists of seminars, lectures, and interdisciplinary colloquia; whereas, Perspectives in Western Civilization is a leaner overview of philosophy and theology with an embedded information literacy component. In contrast to the two full years of study that fulfill the DWC requirement for Day Students, the Perspectives in Western Civilizations course is a single semester and covers only theology and philosophy.

The information literacy requirement for this class was written by the School of Continuing Education, and requires a partnership with a research librarian to ensure that at the end of the course students meet the following criteria:

- Student will be able to use library and other information sources (databases, search engines, etc.) responsibly to secure secondary sources for written assessments that they would write as part of the course.

- Student will be able to evaluate sources critically to determine the relevance, reliability, and worth of selected resources to the student's own project/paper, etc.

- Student will demonstrate sufficient ethical and legal understanding of copyright and originality guidelines and laws in learning and constructing approved citations of sources for written projects or papers (e.g., in constructing an approved Works Cited or Bibliography section).

To date the library has partnered with this class in the fall 2014, fall 2015, and spring 2016 semesters for at least two meetings each time, though three meetings are preferred.

The first meeting covers a basic overview of library resources including the catalog, Research Guide (in particular the Research Guide for SCE students), remote library access, printing, setting up a research appointment, and researching in the Academic Search Complete database. Since the nontraditional student population has not, for the most part, conducted any kind of library research in many years, this session is typically slower paced than a traditional fiftyminute one-shot session with students from the Day School. This also ties in with Mellon's theory that a traditional fiftyminute one-shot is not sufficient to quell library anxiety or to make the library and librarian more approachable. Additionally, since this class is primarily taught by adjunct faculty, the instructors are often not as familiar with Providence College resources as regular faculty may be, and therefore it's even more crucial that students leave the class with a good grasp of how to access articles and books. Each session concludes with a brief assignment where the students put their new knowledge into practice. For the first session assignment, students locate an article pertinent to the current class readings and print out the first page of that article.

This initial assignment was constructed with three goals in mind to help ease SCE students into using the library:

- Since most students, if not all of them, have no experience with using research databases, the assignment forced them to interact with the databases immediately after witnessing a demonstration, hopefully cementing in their minds how to use them and removing a bit of library anxiety.

- This first interaction with databases occurred in a safe space where there were experts on hand (librarians and professors) to answer questions and address issues as they came up. This served to bolster the confidence of the students, and make them more secure in their ability to access these resources on their own.

- This also forced students to interact with the printing system, known as PC Prints. PC Prints is a Pharos remote printing system that requires SCE students to either buy a print card or load money to their PC ID to use. There is a bit of a learning curve, and a real danger of technostress, but requiring them to interact with a printing system in a more controlled environment with experts available should help with quelling printing anxiety.

The second session for the Perspectives class is about issues of academic integrity and citation. Providence College has a stated Academic Integrity policy, which is also communicated in an online tutorial that all incoming Day Students must take. This is replicated for SCE students through a lecture that discussed various definitions related to academic integrity, examples of how to cite properly using MLA, how to paraphrase, cautionary tales of the consequences of violating academic integrity, and a list of resources available to students to help them learn to cite properly. As with most of the lessons for this group of students, efforts are made to tie academic work to real-life situations to satisfy older learners' need to know, as described by Knowles. At Phillips Memorial Library, we recommend students consult Purdue's Online Writing Lab (OWL) for citation help, and we pay for access to RefWorks citation management software.

The assignment for the second session is to set up a RefWorks account. Once the account is created, the student is to go back into the SCE Research Guide to locate a database and search for another article related to their paper topic. Depending on when the second session occurs in the semester, students may have already been working on a research paper, so this gives them time in class and with help to do more research into what scholarship is available. Once they have located an article, they must import it into RefWorks and print off the page that shows what article they imported. This assignment's learning outcomes are that students

- build on previous knowledge of Research Guides, locating a database, and searching in a database;

- build on previous knowledge of the print system PC Prints; and

- establish a familiarity with RefWorks and realize that using it is strongly recommended by both the professor and the librarians.

The third session focuses on evaluating and incorporating 
sources into a research paper. We begin with a short video about the research process that deals with coming up with a research question. After that, the students are instructed to think about their own research question and look for articles that would support it. This session focuses on the students doing research on their own with help from librarian and professor. The assignment is to locate an article, print off the citation, and list five reasons why it is an appropriate article for their research question. The educational outcomes for the third session are the following:

- Build on previous knowledge of database searching to boost confidence in research skills and continue to hone database navigation techniques.

- Build on previous knowledge of the print system PC Prints. By the third session, most students have purchased print cards and are able to print without assistance.

- Require students to take time and really analyze why one article may be more appropriate than another, rather than just gathering the prescribed number of sources and writing the paper.

- Encourage the students to come up with a research question and look for supporting articles with the knowledge that their research question may change depending on the scholarship available. Making sure that they understand trial and error is part of the research process.

By the third session, students are significantly more comfortable with library databases, with using the printing system, and with how and when to reach out if they need help. Since most of our remote reference doesn't give us an indication of the student's age, it's hard to tell if there was an increase in questions from SCE students. Anecdotal evidence indicates that they are much more comfortable reaching out to the library, and they have a better understanding of the value of library resources and services.

\section{LIBRARY INSTRUCTION AT PROVIDENCE COLLEGE}

Library instruction at Providence College, with the exception of the Perspectives in Western Civilization course, is at the request of faculty. We have many professors and disciplines that we work with every semester, primarily English, Theology, Social Work, and Education, but some departments request our services less frequently or not at all. In the past, the Research and Education department in the library had subject specialist liaisons, but as we are such a small staff, maintaining that type of arrangement became unwieldy due to an imbalance among the demand for instruction by discipline. Now we operate on a less rigid model where most requests come to the coordinator for face-to-face instruction, and then librarians sign up for sessions that interest them and work with their schedules. This provides a more equitable solution for library staff in terms of time, interests, and teaching demands, and gives faculty a chance to work with multiple members of library staff.

Traditionally, most of our library instruction sessions have been for the students in the Day School. Day School students are traditional undergraduates, ages seventeen to twenty-one, who primarily live on campus. Day School classes are primarily taught by normal faculty, though students enrolled in the Day School may occasionally take classes through the SCE. As classes in the SCE are primarily taught by adjunct faculty, many are unaware of the services the library offers with regard to instruction, and many do not actually use our library at all. The Perspectives in Western Civilization class is the first class that has had required library instruction built into the syllabus.

The library also has a position that serves as the liaison to the School of Continuing Education, and though we have worked with them for many years trying to find effective ways to reach out to their students, it has been a considerable challenge to sell our services to a student population with such varying technology skills, demands on their time outside of school, and lack of understanding as to what the library offers. This position is the only remaining vestige of a liaison program in the library. Maintaining the liaison to SCE is not a tremendous burden in terms of the amount of time spent but the library staff member in that role must be focused on outreach since this is a population of students who don't use the library heavily. Similar to the Day School students, SCE students need to first be encouraged to use the library by their professors for them to understand its value.

To reach out to this population, we've taken several steps during the 2015-16 school year:

- We modified and improved a Research Guide specifically geared toward SCE students in fall 2015. This guide has been in existence since 2013, but after improving it and increasing our instruction to SCE students use of the guide increased from 78 views (fall 2013) to 42 views (fall 2014) to 340 views (fall 2015). This guide includes information as to how to find books and articles in several multi-disciplinary databases. It also includes more information that is unique to SCE students, such as how to get a library card, how to print on campus, the benefits and privileges that come with being a Providence College student with regard to access to information, and a virtual tour with pictures of different places in the library that they might want or need to use over their time at Providence College.

- The library liaison to SCE worked with a marketing consultant to better sell the library to prospective students. PC is undergoing a campus-wide website redevelopment, and SCE hired a marketing firm to help create more useful materials for current and prospective students. The library liaison worked with the marketing consultant to come up with language that explains to this unique population why they should seek out help from the library 


\section{FEATURE}

over the course of their time at PC. Reasons included were the following:

- Unique collections that support the PC curriculum

- Library staff who are well-versed in helping with scholarly research

- Long hours to accommodate both work and school schedules

- Significantly more access to research materials appropriate for scholarly research than a public library would have

- Access to massive e-book collections and scholarly databases that can be used from home.

- We worked with the SCE advisor to offer library tours to interested students. These included physical tours of the building, but also an overview of online resources available to them from home as well as information about how to contact a librarian remotely or set up a research appointment. The tours were offered two different nights, to better accommodate working students' schedules and also to indicate to them that research assistance and other library services are available seven days a week. The library is typically open 8 a.m.-2 a.m. on MondayThursday, 8 a.m. -10 p.m. on Friday, 9 a.m.-10 p.m. on Saturday, and 9 a.m.-2 a.m. on Sunday. Sunday with research assistance available on a drop-in basis most days from 8:30 a.m.-10 p.m. We also extend library hours for mid-terms and pre-finals, staying open until 3 a.m. and offering drop-in research assistance until 11 p.m. During finals, the library is open twenty-four hours a day for about ten days, with research assistance available until 11 p.m.

- We worked with the SCE advisor to include physical copies of library information handouts (library FAQ sheets) in the initial packet of information that students receive. This FAQ sheet provides an overview on how the library works, what services we offer, how to get a library card, hours, and how to contact a librarian.

- We've increased the amount of email and face-to-face communication with SCE to keep the conversation going about changes, updates, and new ideas. The library liaison met with the Dean of SCE and the SCE advisor in fall 2015 to brainstorm new ideas for outreach, and since that meeting, have emailed regularly with ideas and strategies.

- We've requested copies of syllabi from SCE faculty to see what kind of assignments they are requiring their students to do. The hope is to create relationships with faculty who teach regularly in SCE and to either get invited into class for library instruction, or have the faculty refer their students to the library (physically or virtually) for research help. Since many faculty assign their students research papers, but do not request library instruction, we hope to understand how their students are currently doing research, and find ways to help them improve in their methods.

- Many of the classes taught through SCE are wholly online or hybrid classes using Sakai Learning Management System. We plan to embed library information in the form of a Research Guide into all course shells in fall 2016. This should serve as another way for SCE students to find their way to the library's resources, even if they're not directed to them by faculty.

\section{FURTHER EFFORTS}

In the 2016-17 school year, we're hoping to continue the outreach we've already done, as well as a few new targets. There is an SCE advisory committee run by the college. Our library's SCE liaison has requested to be appointed to that committee. This is a presidential appointment, and a member of library staff are already on the committee, so there is a chance that the appointment won't go through, but compelling arguments have been made, and we're waiting to find out the outcome. Also, we have been working with the Dean of Graduate and Undergraduate Education to create a one-credit library research class. This is a class that would likely be run by SCE, but it would be open to all students. Once the course has been created, we can promote it to SCE faculty to recommend it to their students, and also mention it in the Perspectives in Western Civilization class to try to increase awareness among SCE students.

We ask other institutions who have nontraditional students to evaluate the services they currently offer to that population, and come up with outreach strategies that work for their unique institution. We'd like to have a larger conversation about how to best serve this critical and potentially overlooked segment of our student body.

\section{CONCLUSION}

We are pleased with the efforts we have made so far and the outcomes we've gotten. Targeting SCE students is a logical extension of the library's mission, and from what we learned in completing a review of the literature, a targeted outreach effort is essential in reaching this unique population. Now that we have more momentum and ideas of what works, we intend to continue our current outreach efforts and hopefully expand our understanding of SCE students and faculty needs by serving on the SCE advisory committee, meeting more faculty, both face-to-face and virtually, promoting library services to them, and continuing work with the Perspectives in Western Civilization class. There is more to do, but we have a good foundation to build on.

It's important to note that this is a relatively simple endeavor for library staff that will actually have a massive impact on students in the School of Continuing Education for the rest of their time at PC. The Perspectives in Western Civilization course is taken by most SCE students, regardless of their program track, and for the 2016-17 school year, the course was expanded into two sections with about forty 
students total. Anecdotal evidence from current and past students as well as faculty supports the idea that having structured, embedded library instruction significantly reduces library anxiety, which improves educational outcomes for students.

Faculty may initially be hesitant to give up class time, but this is a program that can be scaled up or down depending on the institution. Something as simple as the librarian attending class, introducing him, or herself and explaining how the role of the academic library is a good starting point. Using the course's learning management system is also a good way to reach out, though it may not be helpful to those students who are already behind technologically, so face-toface interactions whenever possible are crucial. As we have found, any reluctance on the part of faculty to partner with the library goes away quickly after seeing the improvement in student work and confidence.

\section{References}

1. Malcolm S. Knowles, "The Future Role of Libraries in Adult Education" (lecture, Continuing Library Education Network and Exchange Assembly, Chicago, January 23, 1976), Southeastern Librarian 47 (Winter 1975): http://eric.ed.gov/?id=ED118133.

2. Nicole A. Cooke, "Becoming an Andragogical Librarian: Using Library Instruction as a Tool to Combat Library Anxiety and Empower Adult Learners," New Review of Academic Librarianship 16, no. 2 (2010): 208-27, https://doi.org/10.1080/13614533.20 10.507388 .

3. Ibid

4. Ibid., 209.

5. Naomi Harrison, "Breaking the Mold: Using Educational Pedagogy in Designing Library Instruction of Adult Learners," Reference Librarian 33, no. 69-70 (2000), https://doi.org/10.1300 /J120v33n69_26

6. Ibid., 289

7. S. Malcolm, Elwood F. Holton III, and Richard A. Swanson, The Adult Learner: The Definitive Classic in Adult Education and Human Resource Development (Abingdon, UK: Routledge, 2011).
8. Ibid., 63.

9. Ibid., 65 .

10. Ibid., 66

11. Michel C. Atlas, "Library Anxiety in the Electronic Era, or Why Won't Anybody Talk to Me Anymore?," Reference \& User Services Quarterly 44, no. 4 (Summer 2005): 315.

12. Constance A. Mellon, "Library Anxiety and the Non-traditional Student," in Reaching and Teaching Diverse Library User Groups: Papers Presented at the Sixteenth National LOEX Library Instruction Conference Held at Bowling Green State University, edited by Teresa B. Mensching (Ann Arbor, MI: Pierian, 1989), 78.

13. Constance A. Mellon, "Library Anxiety: A Grounded Theory and Its Development," College \& Research Libraries 47, no. 2 (1982): 163, http://crl.acrl.org/content/47/2/160.

14. Ibid., 162.

15. Ibid., 164

16. Brian Quinn, "Overcoming Technostress in Reference Services to Adult Learners," Reference Librarian 33, no. 69-70 (2000): https://doi.org/10.1300/J120v33n69_05.

17. Charlotte Diana Moslander, "Helping Adult Undergraduates Make the Best Use of Emerging Technologies," Reference Librarian 33 no. 69-70 (2000): 105

18. Quinn, "Overcoming Technostress in Reference Services to Adult Learners."

19. Ibid., 12.

20. Cooke, "Becoming an Andragogical Librarian," 217.

21. Ibid., 220.

22. Ibid., 222.

23. Ibid., 219.

24. Ibid., 223.

25. Jessica Lange, Robin Canuel, and Megan Fitzgibbons, "Tailoring Information Literacy Instruction and Library Services for Continuing Education," Journal of Information Literacy 5, no. 2 (2011): 68 .

26. Lauren Hays, "Teaching Information Literacy Skills to Nontraditional Learners," Kansas Library Association College and University Libraries Section Proceedings 4, no. 1 (2014), https://doi .org/10.4148/2160-942X.1036. 